\title{
Model Sistem Informasi Manajemen Dosen Sekolah Pascasarjana Universitas Pendidikan Indonesia Berbasis IR 4.0
}

\section{Model of Management Information System for Lecturers of Postgraduate School Indonesian University of Education Based on IR 4.0}

\author{
Eka Prihatin*, Ratu Dintha IZFS \& Raja Pasha AZFS \\ Universitas Pendidikan Indonesia, Bandung, Jawa Barat, Indonesia \\ ekaprihatin@upi.edu*
}

Naskah diterima tanggal 25/11/2020, direvisi akhir tanggal 25/12/2020, disetujui tanggal 31/12/2020

\begin{abstract}
Abstrak
Sistem Otomasi yang menjadi ciri Era Revolusi 4.0 menjadi trend global dalam berbagai aspek kehidupan, terlebih lagi dalam dunia pendidikan. Era ini menyingkirkan sistem manual menjadi sistem yang otomasi melalui aplikasi yang dirancang sempurna. Dosen pascasarjana merupakan aset unggul, istimewa dan professional yang dimiliki oleh perguruan tinggi, karena kualifikasi dan kompetensi yang sempurna untuk melakukan layanan akademik mahasiswa program magister dan program doctor, akan tetapi asset sumber daya manusia yang hebat dan sempurna ini akan memberikan kualitas kinerja dan produktivitas setinggi-tingginya, jika dimanfaatkan dan diberdayakan secara tepat dan terarah. Namun banyak pimpinan program studi yang menyia-nyiakan asset berharga ini melalui kesalahan strategi dalam pengambilan keputusan, sehingga terjadi pemborosan sumber daya berharga yang berdampak pada kerugian besar bagi program studi tersebut. Penelitian ini menelaah 54 program studi magister dan doctor untuk menelaah pemborosan dosen pascasarjana melalui mixed methods. Hasil penelitian menunjukkan bahwa $72 \%$ program studi yang terbukti tidak mengoptimalkan produktivitas dosen pascasarjana, sehingga secara sah dan meyakinkan terjadi pemborosan sebesar $58,01 \%$.
\end{abstract}

Kata kunci: Aplikasi; Pengelolaan; Dosen; IR 4.0; SIM.

\begin{abstract}
The automation system which characterizes the Revolutionary Era 4.0 is a global trend in various aspects of life, especially in the world of education. This era eliminates manual systems into automated systems through perfectly designed applications. Postgraduate lecturers are superior, special and professional assets owned by universities, because of the perfect qualifications and competencies to perform academic services for students of master and doctoral programs, but this great and perfect human resource asset will provide the highest quality of performance and productivity. -the highest, if used and empowered in an appropriate and directed manner. However, many study program leaders waste this valuable asset through a strategic mistake in decision making, resulting in a waste of valuable resources which results in huge losses for the study program. This research examines 54 master and doctoral study programs to examine the waste of postgraduate lecturers through mixed methods. The results showed that $72 \%$ of study programs were proven not to optimize the productivity of postgraduate lecturers, so that legally and convincingly there was a waste of $58.01 \%$.
\end{abstract}

Keywords: Application; Management; Lecturer; IR 4.0; SIM. 


\section{PENDAHULUAN}

Era revolusi 4.0 menjadi trend global yang melanda berbagai sektor kehidupan, demikian juga dengan dunia pendidikan, mau tidak mau harus mengikuti trend ini, terlebih lagi dengan pascasarjana yang menitikberatkan lulusannya memiliki kompetensi sesuai dengan tuntutan DUDI. Dimana tujuan mengikuti pascasarjana untuk lebih mengembangkan lagi potensi dirinya sehingga mampu berkompetisi secara global, sehingga trend global menjadi acuan dalam menyusun rencana strategik setiap prodinya.

Era IR 4.0 didominasi dengan internet of thing, sehingga Sekolah Pascasarjana UPI harus menjadi pelopor dan model sistem informasi manajemen yang terkini memenuhi tuntutan IR 4.0. Model ini diusung dengan sistem otomatisasi dalam (1) pembimbing akademik; (2) pengampu mata kuliah; (3) pembimbing tesis dan disertasi; (4) penguji tesis dan disertasi.

Sistem yang berjalan memiliki dampak yang menimbulkan berbagai permasalahan yang pada akhirnya akan mempengaruhi kinerja dosen sebagai tenaga pendidik di pascasarjana. Contoh kasus di Administrasi Pendidikan setiap rapat awal perkuliahan selalu ada permasalahan berkaitan dengan (1) mata kuliah yang diampu, belum lagi adanya dosen sebagai tenaga professional yang tidak mendapatkan jadwal matakuliah, dan yang lainnya. Kebijakan ketua prodi sebagai pimpinan yang menentukan pengampu setiap mata kuliah menjadi penyulut konflik yang berakibat pada tersendatnya kinerja dan kekompakkan prodi; (2) Ketidakpuasan dosen kepada pimpinan yang lainnya adalah perbandingan yang tidak merata antar dosen dalam pembimbing akademik, ada dosen yang menjadi pembimbing akademik untuk 1 atau 2 orang, namun ada beberapa dosen yang menjadi pembimbing akademik sampai dengan 7 orang; (3) penunjukkan pembimbing pada tesis dan disertasi memperlihatkan rasio yang sangat menarik antara satu dosen dengan dosen lainnya. Ketua prodi : beberapa dosen: dosen lainnya adalah $80 \%$ : $60 \%$ : kurang dari $10 \%$. Sehingga pengambilan keputusan pimpinan dalam menentukan pembimbing dipertanyakan standar yang dipergunakan; (4) begitu juga dengan rasio dosen dalam menguji tesis dan disertasi memiliki perbedaan yang mencolok antara ketua prodi : Beberapa dosen: dosen lainnya yaitu 99\%: 80\%; 10\% dari jumlah mahasiswa yang mengikuti ujian tesis dan disertasi dalam beberapa tahun terakhir ini.

Permasalahan tersebut hanya bagian kecil saja yang muncul hampir disetiap semester yang akan berdampak pada kualitas proses pembelajaran yang pada akhirnya akan mempengaruhi pengembangan kompetensisi mahasiswa yang tidak optimal dan komprehensif, dan pada akhirnya menciptakan ketidakpuasan customer sehingga akan menurunkan animo calom customer untuk memilih UPI sebagai tempat proses pendidikan, sehingga citra UPI akan menurunkan tingkat kepercayaan dari masyarakat, government, stakeholders dan users sebagai pengguna lulusan UPI.

Alternatif penyelesaian permasalahan tersebut adalah dengan model SIM berbasis komputer sesuai dengan tuntutan IR 4.0 dimana secara cepat manualisme diganti dengan teknologi.

Perubahan disruptif di dunia global dengan masuknya periode revolusi industri yang ke empat (Revolusi Industri 4.0) telah memberikan dampak yang sedemikian besarnya, tidak hanya pada dunia industri namun juga pada dunia pendidikan tinggi. Era industri 4.0 ditandai dengan beberapa hal antara lain makin berperannya Internet of Things (IoT) pada setiap industri dan bisnis, dan makin ekstensifnya pemakaian robot dan sensor pada sistem industri dan produksi, serta perubahan lainnya.

Pemerintah RI telah merespon issue ini dengan meluncurkan roadmap industri 4.0 pada tanggal 4 April 2018 di Jakarta Convention Center (JCC) Senayan. Roadmap industri 4.0 ini merupakan peta jalan pemerintah untuk menuju ekonomi digital dan diharapkan mampu mendukung perekonomian. Ada lima sektor prioritas yang masuk dalam roadmap industri 4.0, yakni makanan minuman (mamin), elektronik, otomotif, tekstil, footwear, dan kimia. Pemerintah menganggap diperlukan koordinasi regulasi maupun insentif fiskal terkait infrastruktur telekomunikasi. Pada saat 
yang sama, beberapa kementerian juga merespon roadmap industri 4.0, termasuk Kementerian Riset, Teknologi dan Pendidikan Tinggi.

Belum lagi persaingan dalam institusi perguruan tinggi nampak semakin ketat. Perubahan dunia yang begitu cepat dalam hal kemajuan teknologi (produk, jasa maupun proses) serta kehidupan sosial ekonomi masyarakat, mendorong perlu diadakannya suatu langkah antisipasi melalui kebijaksanaan dan strategi perguruan tinggi agar nantinya tetap bisa survive dalam segala bidang. Keberhasilan suatu perguruan tinggi tidak hanya dilihat dari satu faktor saja, tetapi banyak faktor yang menentukan keberhasilan tersebut. Baik itu faktor internal maupun faktor eksternal. Faktor internal meliputi jumlah dan kualitas dosen yang memadai, sarana dan fasilitas yang menunjang, mahasiswa sebagai motor pengggerak yang berpotensi, pelayanan yang memuaskan dan lain-lain. Sedangkan faktor eksternal adalah hubungan perguruan tinggi dengan masyarakat, pemerintah dan perguruan tinggi lainnya.

Universitas Pendidikan Indonesia (UPI) sebagai salah satu perguruan tinggi terbaik di Indonesia, tentunya memiliki kewajiban untuk merepson hal tersebut untuk secepatnya dapat beradaptasi dengan arah perubahan dalam upaya menghasilkan sistem dan lulusan yang mampu bersaing dan berperan di era Revolusi Industri 4.0. Untuk menjawab tantangan tersebut, khususnya perguruan tinggi, harus pula berubah. Semua pemangku kepentingan di perguruan tinggi harus mau berubah. Dosen, tenaga kependidikan, dan mahasiswa harus berubah. Semua pihak harus berupaya meningkatkan kompetensi diri, terus belajar, dan menyesuaikan dengan kebutuhan era ini.

Beberapa hal yang dilaksanakan oleh UPI dalam menyongsong issue IR 4.0, antara lain: pengembangan sistem pembelajaran yang inovatif; penyesuaian kurikulum pembelajaran dengan pendekatan human digital dan keahlian berbasis digital; peningkatan kemampuan mahasiswa dalam menguasai data Informasi Teknologi (IT), Operasional Teknologi (OT), Internet of Things (IoT), dan big data; pengintegrasian 409 objek fisik, digital, dan manusia secara komprehensif; dan peningkatan kualitas lulusan yang menguasai aspek literasi data, literasi teknologi, dan literasi manusia.

Beberapa tantangan pada era industri 4.0 diidentifikasi sebagai berikut; 1) peningkatan keamanan teknologi informasi; 2) peningkatan keandalan dan stabilitas mesin produksi; 3) peningkatan keterampilan; 4) keengganan para pemangku kepentingan untuk berubah; dan 5) hilangnya banyak pekerjaan karena adanya otomatisasi (Sung, 2017, dalam Yahya, 2018). Tetapi tantangan lain yang dihadapi oleh sekolah pacasarjana UPI adalah belum adanya sebuah model sistem informasi manajemen yang terkait dengan pelayanan dosen mulai dari (1) pembimbing akademik; (2) pengampu mata kuliah; (3) pembimbing tesis dan disertasi; (4) penguji tesis dan disertasi.

Pemanfaatan sistem informasi untuk setiap aktivitas internal dalam perguruan tinggi akan juga menjadi faktor kesuksesan dan kemajuan dari perguruan tinggi. Banyak hal yang bisa dilakukan dengan sistem informasi seperti sistem informasi akademik yang mengatur data jadwal belajar mengajar, dosen, mahasiswa dan nilai mahasiswa. Dengan adanya sistem informasi juga akan sangat memudahkan perguruan tinggi menghasilkan informasi terkait di atas dan memudahkan segala aktivitas perguruan tinggi terkait dengan pengolahan data. Informasi didapatkan dari sistem informasi (information system) yaitu sebuah sistem di dalam organisasi yang mempertemukan kebutuhan pengolahan transaksi harian dalam mendukung kegiatan operasional baik yang bersifat manajerial maupun berupa kegiatan strategi yang mampu menyediakan laporan - laporan berupa informasi kegiatan kepada pihak yang berkepentingan (Muhammad Taufiq).

Terdapat lima indikator kunci kinerja yang harus memenuhi standar minimal kriteria kelayakan dalam pengelolaan/ manajemen, yaitu: 1) Penyelenggaraan program pendidikan tinggi seperti sistem dan mekanisme kerja; 2) Infrastruktur seperti tanah, gedung, peralatan dan fasilitas lainnya; 3) Finansial seperti struktur pemasukan, pengeluaran dan penggunaan dana; 4) Aset sumber daya manusia seperti sistem rekruitmen mahasiswa, rekuitmen dan pengembangan staf pengajar Jurnal Penelitian Pendidikan 
serta staf pendukung lainnya; dan 5) Informasi seperti online internal connectivity melalui sistem informasi manajemen yang baik.

Keberadaan SIM PT dapat pula menjadi tolok ukur kesiapan dalam memasuki era informasi perguruan tinggi. Sebagai langkah awal dalam upaya mempersiapkan perguruan tinggi tersebut, perlu dimulai dengan membangun jaringan informasi yang berbasis pangkalan data untuk mendapatkan informasi pendataan di setiap unit-unit kerja di lingkungan perguruan tinggi. Data yang absah, lengkap dan aktual merupakan masukan utama untuk menghasilkan informasi yang benar, akurat, serta mutakhir, yang pada akhirnya bermuara pada keputusan/ kebijakan yang dapat di terima, tepat sasaran, serta tepat waktu. Namun, kegiatan penyediaan dan pengolaan data, khususnya di bidang pendidikan tinggi masih memiliki permasalahan.

PT sebagai suatu sistem yang sangat besar, memiliki sub-sub sistem yang banyak sehingga masing-masing membentuk pola hubungan kerja yang mewujudkan sebuah sentralisasi sistem yang bekerja secara harmonis, saling dukungmendukung dan terkait satu dengan yang lain. SIM-PT diharapkan dapat menjadi salah satu solusi yang dapat membantu menyelesaikan permasalahan-permasalahan manajemen di setiap tata kelola PT yang ada.

Untuk menghasilkan sebuah sistem informasi agar terintegrasi dengan baik perlu diperhatikan tiga hal: Pertama, sistem informasi didefinisikan secara jelas dan terperinci sehubungan dengan jenis- jenis informasi apa yang dibutuhkan oleh institusi. Halhal yang berkaitan dengan kecepatan proses pengolahan data menjadi informasi, tingkatan detail informasi, cara penampilan informasi. Kedua, adanya teknologi infrastruktur, alat komunikasi, dan lain-lain) dan perangkat lunak (aplikasi, sistem operasi, database, dan lain-lain) yang harus tersedia. Ketiga, adanya manajemen informasi, yang menyangkut perangkat manusia (brainware) yang akan mengimplementasikan sistem informasi yang dibangun dan yang akan mengembangkan teknologi informasi.

Karakteristik SIM-PT adalah menjadi Jurnal Penelitian Pendidikan sarana pendukung lembaga pendidikan tinggi untuk mencapai tujuan memberikan layanan yang diperlukan masyarakat akademis secara memuaskan, andal dan terjangkau, menaikkan mutu pelayanan sesuai dengan misi pendidikan tinggi, dan memberikan informasi yang akurat dan luar institusi.

\section{METODE PENELITIAN}

Penelitian ini menggunakan desain Convergent parallel mixed methods untuk memberikan analisis komprehensif terhadap masalah penelitian (Creswell, 2014). Dengan fokus bahasan yaitu program studi magister dan doctor tentang tingkat pemborosan sumber daya yaitu dosen pascasarjana yang mengerucut pada tingkat pemberdayaan dan pemanfaatan SDM dalam bidang pendidikan yaitu bagaimana pimpinan memetakan dosen sebagai pengampu mata kuliah, bagaimana pimpinan memetakan dosen memiliki tugas sebagai pembimbing akademik, bagaimana pimpinan memetakan dosen sebagai pembimbing tesis dan disertasi; dan bagaimana pemimpin menugaskan dosen sebagai penguji tesis dan disertasi.

Kriteria umum untuk sampel penelitian ini meliputi (1) dosen pascasarjana ; (2) mengampu mata kuliah di program magister; (3) mengampu mata kuliah di program doctor; (4) Pegawai Negeri Sipil di Perguruan Tinggi. Akhirnya dipilih ada 37 dosen yang memenuhi kriteria di atas mewakili setiap program studi yang memiliki jenjang magister dan doctor, dimana dosen tersebut dipilih secara rendon dari dosen yang memenuhi kriteria dari setiap program studi. 37 dosen yang menjadi responden $(\mathrm{n}=37,100 \%)$ terdiri dari 8 perempuan $(21,62 \%)$ dan 29 laki-laki $(78,38 \%)$ - kualifikasi pendidikan semua responden adalah doctor, dengan jabatan fungsional yang berbeda yaitu lector 5 orang $(13,51 \%)$, sedangkan lector kepala 20 orang (54.05), dan professor sebanyak 12 orang $(32.44 \%)$. 


\section{HASIL DAN PEMBAHASAN}

\subsection{Hasil}

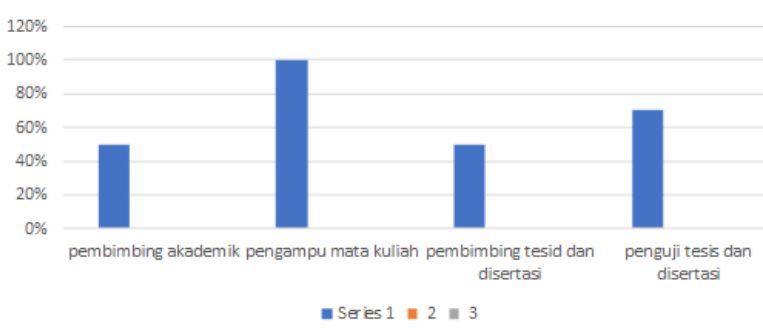

Gambar 1. Hasil penelitian tentang analisis pembimbing akademik SPs UPI

Data gambar 1 menunjukkan bahwa tingkat pemerataan dari pembimbing akademik dari jumlah siswa dan jumlah dosen yang diberi tugas sebagai pembimbing akademik hanya 50\%. Artinya tidak semua dosen mendapatkan tugas sebagai pembimbing akademik, dimana hampir disemua prodi terjadi penunpukan pada beberapa dosen sementara dosen yang lainnya tidak diberi tugas untuk menjadi pembimbing akademik. Hal tersebut menunjukkan bahwa ketua prodi sebagai pembuat keputusan dengan kewenangannya telah membuat langkah pemborosan sumber daya professional yang dimiliki oleh universitas. Dampaknya adalah kerugian besar bagi perkembangan kualitas universitas akibat tidak dipergunakan/ dimanfaatkan sumber daya professional secara optimal.

Tingkat pemerataan penyebaran mata kuliah mencapai $100 \%$ dalam arti bahwa setiap program studi telah mempergunakan/ memanfaat seluruh sumber daya profesional yang dimiliki universitas. Keputusan menggunakan semua sumber daya tiap program studi merupakan langkah bagus sehingga menghindari pemborosan aset sumber daya professional yang dimiliki oleh universitas

Pemerataan pembimbing tesis dan disertasi sangat rendah hanya $50 \%$, artinya ketua prodi membuat keputusan pembimbing tesis dan disertasi tidak merata dan hanya bertumpu pada beberapa dosen saja, sehingga dapat dipastikan terjadi pemborosan sumber daya professional yang tidak dipergunakan, dengan asumsi bahwa semua dosen pascasarjana adalah tenaga professional yang telah memiliki syarat sesuai ketentuan kebijakan universitas.

Demikian juga pada penguji tesis dan disertasi, tingkat pemerataannya hanya $70 \%$, dalam arti tidak semua dosen sebagai sumber daya professional yang dimiliki setiap prodi dipergunakan untuk menjadi penguji, bahkan di banyak prodi penguji bertumpuk pada sebagian dosen/ sumber daya professional. Disinipun keputuisan ketua prodi telah mendorong pemborosan sumber daya professional yang dimiliki universitas akibat tidak dipergunakan kebermanfaatan sumber daya professional secara optimal.

Solusi yang diajukan adalah 4 kegiatan di atas yaitu (1) pembimbing akademik; (2) pengampu mata kuliah; (3) pembimbing tesis dan disertasi; serta (4) penguji tesis dan disertasi dilakukan secara otomatisasi. Asumsi yang dirujuk adalah bahwa semua dosen pascasarjana adalah sumber daya professional sebagai aset universitas, dengan demikian untuk menghindari tidak terpakai secara optimal yang akan mengakibatkan pemborosan dan kerugian yang besar bahi universitas karena terbuangnya sumberdaya professional, maka dibuat sebuah sistem yang akan mengakomodir penggunaan berdasarkan keahlian sumber daya professional tersebut.

Dengan demikian pengelolaan dosen pascasarjana di Universitas Pendidikan Indonesia masih belum bagus, karena hampir setiap program studi melakukan pemborosan aset universitas dengan pemberian tugas yang menumpuk pada beberapa orang dan tidak mempergunakan semua sumber daya yang dimiliki universitas. Permasalahan ini sangat penting untuk segera ditindaklanjuti dengan model pengelolaan dosen pascasarjana yang bersifat otomasi dengan membagi beban kerja secara merata pada semua sumber daya professional yang dimiliki setiap prodi sebagai aset universitas. Sistem otomasi dibangun untuk menghindari penumpukan beban kerja dan pemborosan sumber daya professional sebagai sistem informasi manajemen (smart system) yang akan membantu pengambilan keputusan kerja ketua program studi sebagai lankah strategic menghindari pemborosan sumber daya professional.

Gambaran diatas tidak akan terlepas dari produktivitas yang menjadi salah satu ukuran kemampuan dan reputasi organisasi apapun di Jurnal Penelitian Pendidikan 
seluruh dunia, demikian juga dengan perguruan tinggi sebagai salah satu organisasi pendidikan, pengukuran produktivitas berdasarkan kinerja. Pemimpin yang hebat adalah pemimpin yang mampu mengoptimalkan sumber daya yang dimiliki untuk mendapatkan hasil yang sebesarbesarnya. Program pascasarjana, dosen memiliki 3 kewajiban yaitu pendidikan, penelitian dan pengabdian masyarakat. $17 \%$ kewajiban dosen adalah melakukan penelitian dan $8 \%$ merupakan kewajiban dosen untuk melakukan pengabdian kepada masyarakat, serta $75 \%$ tugas dosen adalah pendidikan.

Dari 12 kegiatan dosen dalam bidang pendidikan yang umum dilakukan oleh semua dosen pascasarjana adalah melaksanakan perkuliahan, membimbing tugas akhir penelitian dan menguji pada ujian akhir. (Andy-Wali \& Wali, 2018; Ellis et al., 2010; Harackiewicz \& Hulleman, 2010; Lierse, 2016; Park, 2003; Su \& Wood, 2012). Dari pemeriksaan yang dilakukan terhadap file-file surat penugasan dosen, mayoritas dosen tidak merata yang akan berdampak pada kualitas. Bahkan jika penugasan hanya bertumpuk pada beberapa dosen akan berakibat pada penurunan kualitas dan kuantitas layanan akademik.

Semua gambaran ini memunculkan berbagai pertanyaan sebagai berikut: mengapa ketua prodi memutuskan penugasan tidak merata? Apakah dosen mengetahui alasan ketidak-merataan tersebut? Mengapa ketua prodi tidak memetakan seluruh dosen dalam beban kerja yang sama? Beragam pertanyaan tersebut pada akhirnya bermuara pada pertanyaan berikut: apakah ketua prodi memiliki pemahaman dan keterampilan yang baik dalam penggunaan dan pemanfaatan sumber daya secara optimal? Fenomena ini juga dirasakan oleh kolega di tempat kerja. Oleh karena itu, untuk menjawab pertanyaan tersebut melakukan penelitian, dengan tujuan agar ketua prodi menyadari kemampuan dan keterampilan dalam memetakan sumber daya yaitu dosen untuk didorong meningkatkan produktivitas dengan kualitas kinerja yang mumpuni.

\subsection{Pembahasan}

Secara conceptual framework, ketua prodi harus mengenali kualitas kinerja dan kompetensi yang dimiliki dosen, untuk kemudian memetakannya (Asree et al., 2010; Dopson et al., 2016; Kipp, 2008; Russo, 2016; Sydänmaanlakka, 2003) secara proporsional (Schmidt, 2017) dan terarah berdasarkan beban kerja dengan berbasis pada pemanfaatan potensi secara optimal. (Coll, 2008; Igwe, 2014; Okoye \& Ezejiofor, 2013). Berkaitan dengan pemetaan pemebelajaran, pembimbing akademik, pembimbing tesis dan disertasi serta penguji tesis dan disertasi.

Kami melakukan analisis data dari pengumpulan data kualitatif dan data kualitatif dengan menggunakan meta inferensial yang digunakan untuk menggambarkan pernyataan diatas menunjukkan bahwa peran dan tanggung jawab pemimpin sangat besar sekali, karena keputusan pimpinan akan menentukan arah dan tujuan organisasi (Abbas \& Asghar, 2010; Abdulridha Jabbar \& Hussein, 2017; Al Khajeh, 2018; Belias \& Koustelios, 2014; Bucata \& Rizescu, 2016; Jaques, 2018; "Organ. Manag.," 2015; Revenio C. Jalagat, 2017; Saleh, Mohammed et al., 2018; Sherratt, 1991; Thomas, 2017), disamping itu salah satu tugas dan tanggungjawab pimpinan adalah mempergunakan setiap potensi sumber daya yang dimiliki seoptimal mungkin (Bucata \& Rizescu, 2016; "Organ. Manag.," 2015; Revenio C. Jalagat, 2017; Saleh, Mohammed et al., 2018; Sherratt, 1991) sehingga konsep efektif, efisien, produktivitas dan kualitas kinerja seoptimal mungkin dan mendapatkan manfaat serta keuntungan setinggi-tingginya.

Pascasarjana merupakan sekolah yang menyediakan program magister dan program doctor, dimana membutuhkan seperangkat knowledge dan skills dalam mengelola semua sumber daya yang menjadi asset organisasi secara professional dan inovatif juga pada saat bersamaan membangun kolaboratif dan timwork yang solid, andal dan vision. Asset yang menjadi andalan utama adalah sumber daya manusia yaitu dosen pascasarjana yang memiliki kualifikasi pendidikan tertinggi dan profesional untuk melakukan transformasi knowledge yang akan membangun kualitas potensi mahasiswa secara optimal. 
Pimpinan program studi bertanggung jawab memetakan dan memberdayakan setiap dosen yang dimilikinya untuk banyak kegiatan yang harus dilaksanakan sesuai dengan tridharma perguruan tinggi yaitu Pendidikan, Penelitian dan Pengabdian Kepada Masyarakat. Dalam bidang pendidikan ada 4 kegiatan pokok yang harus dilaksanakan yaitu (1) mengampu mata kuliah; (2) pembimbing akademik; (3) membimbing tesis dan disertasi; dan (4) penguji tesis dan disertasi.

Pengampu mata kuliah di setiap program studi memiliki kebijakan dan aturan tersendiri, namun secara garis besar menunjukkan bahwa setiap mata kuliah baik di S2 dan S3 akan diampu oleh Tim dosen yang ditentukan oleh pimpinan, dimana dasar penugasan tersebut salah satunya adalah pilihan dari dosen tersebut, atau permintaan dari ketua tim dosen. Data menunjukkan bahwa 97,06\% sebaran tugas untuk mengampu mata kuliah di program S2 menunjukkan bahwa sebarannya sangat bagus dan mendekati sempurna dalam arti bahwa setiap dosen yang dimiliki program studi hamper semuanya diberdayakan untuk mengampu mata kuliah, demikian juga untuk di program S3 sebaran pemerataan tugas mengajar adalah 94,4\% dengan demikian sebaran tugasnya sangat bagus artinya semua dosen yang sudah memenuhi syarat mengajar di S3 diberi tugas untuk mengampu mata kuliah.

Demikian juga dengan pembimbing akademik, tingkat sebarannya untuk S2 $(\mathrm{n}=34,96,18 \%)$ dan S3 $(\mathrm{n}=20,90,95 \%)$ dalam arti bahwa setiap dosen memiliki jumlah mahasiswa yang hampir sama untuk dibimbing dari mulai masuk sampai keluar (Anyi, 2017; Coll, 2008; Mine et al., 2001; Mporananayo \& Andala, 2018; Ruttoh, 2015)

Membimbing tesis dan disertasi; memiliki tingkat sebaran beban kerja untuk S2 $(n=34,60,76 \%)$ dan untuk S3 $(n=20$, $62,45 \%)$ hal tersebut menunjukkan bahwa tidak semua dosen S2 dan S3 yang diberikan tugas membimbing selain membimbing karena posisi sebagai pembimbing akademik, dengan demikian hanya beberapa dosen yang diberikan penugasan untuk membimbing dalam arti ada penugasan yang bertumpuk 413 pada beberapa dosen baik di jenjang $\mathrm{S}$ 2 maupun di jenjang S3.

Jika ditelaah lebih jauh produktivitas program studi tetap terpenuhi sesuai dengan tuntutan meskipun prosesnya hanya dilaksanakan oleh sebagian dosen saja, akan tetapi jika dilihat dari kinerja, secara sederhana kinerja adalah prestasi kerja merupakan hasil kerja secara kualitas dan kuantitas yang dicapai oleh seseorang dalam melaksanakan tugasnya sesuai dengan tugas pokok dan fungsi serta tanggung jawab yang diberikan kepadanya, Kinerja seseorang merupakan akumulasi dari knowledge, skills, attitude, dan kesempatan serta peluang yang diberikan yang dapat dilihat dari hasil kerjanya(Allaoui mohammed elhassen, Tidjani chemseddine, n.d.; Committee \& Reflections, 2017; Endi Sarwoko, 2013; Garavan \& Mcguire, 2001; Nassazi, 2013; Speiser \& Lang, 2018; Winterton et al., 2006), dan terjadi pemborosan yang dilakukan oleh program studi akibat pendayagunaan dari dosen sebagai asset program studi kurang maksimal, secara sederhana jika dana institusi yang dikeluarkan untuk gaji dosen pascasarjana satu program tertentu adalah $\mathrm{Rp} 100.000 .000 /$ bulan maka kerugian akibat pemborosan sumber daya tersebut adalah $100.000 .000-(60,75 \% \quad \mathrm{X}$ $100.000 .000)=$ Rp.39.250.000/ bulan itu hanya untuk program S2 sedangkan untuk S3 adalah $100.000 .000-(62.45 \% \quad \mathrm{X}$ $100.000 .000)=\operatorname{Rp} 37.550 .000 /$ bulan .

Demikian juga dengan kurang optimalnya pendayagunaan dari sumber daya untuk penguji tesis dan disertasi dimana $\mathrm{S} 2(\mathrm{n}=34$, $55,94 \%)$ dan $\mathrm{S} 3(\mathrm{n}=20,52,9 \%)$ menunjukkan bahwa produktivitas tetap terpenuhi sesuai dengan tugas yang jadi beban hanya saja tidak merata dan bertumpu pada beberapa dosen saja baik untuk S2 dan S3, sedangkan dari sisi kinerja, karena ketidakmerataan penugasan yang diberikan oleh pimpinan maka peluang untuk unjuk kerja menjadi tidak ada untuk dosen yang tidak diberikan penugasan, sedangkan untuk yang memiliki penunpukan tugas maka kualitas kerjanya dipertanyakan, karena jika overload maka akan mengurangi kualitas, artinya kuantitas banyak tapi kualitas menurun. Hal tersebut tentu saja merugikan organisasi, karena yang diusung oleh semua organisasi / perusahaan adalah kualitas produk Jurnal Penelitian Pendidikan 
(Afshar \& Corresponding, 2011; Alanazi, 2016; Halim et al., 2014; Hoe \& Mansori, 2018; Mpele Lekhanya \& Lucky Dlamini, 2017; Nindiani et al., 2018; Razak et al., 2016; Saleem et al., 2015; Shaharudin et al., 2012).

Demikian jika dilihat dari pemborosan yang dilakukan oleh pimpinan program studi karena ketidakmerataan pembagian tugas adalah jika dimisalkan dana yang harus dikeluarkan oleh institusi adalah $\mathrm{Rp}$ 100.000.000/ bulan maka kerugian akibat pemborosan sumber daya tersebut adalah $100.000 .000-(55,94 \% \times 100.000 .000)=$ Rp.44.060.000 / bulan itu hanya untuk program S2 sedangkan untuk S3 adalah $100.000 .000-(52,9 \% \times 100.000 .000)=\mathrm{Rp}$ 47.100 .000 setiap bulannya.

\section{KESIMPULAN}

Simpulan menunjukkan bahwa penugasan yang dilakukan oleh pimpinan terhadap dosen pascasarjana yaitu (1) pengampu mata kuliah; (2) pembimbing akademik; telah m (3) membimbing tesis dan disertasi; dan (4) penguji tesis dan disertasi, menunjukkan bahwa keputusan pemimpin dalam penugasan pengampu mata kuliah dan pembimbing akademik sudah dapat dikatakan sangat baik meskipun belum dapat dikatakan sempurna sehingga kerugian institusi pada 2 kegiatan itu cukup kecil, akan tetapi pemborosan sekecil apapun harus segera ditangani, jika dibiarkan akan menjadi kanker yang ganas pada institusi. Akan tetapi untuk 2 kegiatan lainnya yaitu membimbing tesis dan disertasi, dan menguji tesis dan disertasi. Akibat kelalaian dari pimpinan dalam memeratakan beban kerja, maka organisasi mengalami kerugian yang sangat besar. Akibat pemborosan sumber daya yang dilakukan pimpinan melalui penugasan terhadap dosen maka kerugiannya adalah $58.01 \%$ setiap bulannya.

Dengan demikian keputusan yang diambil oleh pimpinan akan menentukan apakah institusi akan mendapat kerugian atau keuntungan. Pemerataan tugas beban kerja dosen akan membangun iklim yang sangat baik, karena setiap dosen diberi kesempatan untuk melakukan unjuk kerja untuk meningkatkan pertumbuhan universitas, melalui kualitas layanan akademik yang dilakukan. Kualitas layanan dari setiap dosen akan menjadi rantai nilai yang berdampak domino terhadap universitas. Jika layanan dosen berkualitas $\rightarrow$ mahasiswa puas $\rightarrow$ kualitas lulusan $\rightarrow$ terserap dunia kerja $\rightarrow$ stakholders dan penguna lulusan puas $\rightarrow$ kepercayaan masyarakat meningkat $\rightarrow$ calon mahasiswa meningkat $\rightarrow$ pendapatan dan kualitas mahasiswa baru meningkat, demikian seterusnya seperti lingkaran antara aspek yang satu dengan yang lainnya memberi dampak yang hebat. 


\section{DAFTAR PUSTAKA}

Abbas, W., \& Asghar, I. (2010). The Role of Leadership in Organizational Change Relating the Successful Organizational change to Visionary and Innovative Leadership. Industrial Engineering, June, 53.

Abdulridha Jabbar, A., \& Hussein, A. M. (2017). 532 (I2OR) InfoBase Index IBI Factor 3.86 Cite This Article. International Journal of Research-Granthaalayah, 5(5), 99-106. DOI: https://doi.org/10.5281/zenodo.583890

Afshar, A., \& Corresponding, J. (2011). Study of the Effects of Customer Service and Product Quality on Customer Satisfaction and Loyalty PhD Scholar in Business Administration. International Journal of Humanities and Social Science, 1(7), 253-260.

Al Khajeh, E. H. (2018). Leadership styles on organizational performance. Journal of Human Reseources Management Research, 2018, 1-10. DOI: https://doi.org/10.5171/2018.687849

Alanazi, A. (2016). Factors That Affect and Enhance Customer Satisfaction. Quest Journals Journal of Research in Business and Management, 4(9), 80-88.

Allaoui mohammed elhassen, Tidjani chemseddine, O. B. (n.d.). "The Importance of Training Programs in the Improvement of the Performance of Employees in The Petroleum Companies"- Case of Sonatrach Company The Regional Directorate of BERKAOUI (Ouargla- Algeria). Saudi Journal of Business and Management Studies, 787-794. https://doi.org/10.21276/sjbms

Andy-Wali, H. A., \& Wali, A. F. (2018). Lecturers' Leadership Practices and Their Impact On Students' Experiences of Participation with Implications for Marketing Higher Education Services. Higher Education for the Future, 5(1), 40-60. https://doi.org/10.1177/2347631117738640

Anyi, E. M. E. (2017). The Role of Guidance and Counselling in Effective Teaching and Learning in Schools: The Cameroonian Perspective. International Journal of Educational Technology and Learning, 1(1), 11-15. DOI: https://doi.org/10.20448/2003.11.11.15

Asree, S., Zain, M., \& Razalli, M. R. (2010). Influence of leadership competency and organizational culture on responsiveness and performance of firms. International Journal of Contemporary Hospitality Management, 22(4), 500-516. DOI: https://doi.org/10.1108/09596111011042712

Belias, D., \& Koustelios, A. (2014). the Impact of Leadership and Change Management Strategy on Organizational Culture. European Scientific Journal, ESJ, 10(7), 451-470. DOI: https://doi.org/10.1111/j.14678551.2006.00480.x

Bucata, G., \& Rizescu, A. M. (2016). Management Style as a Triggering Factor for Organization Effectiveness and Efficiency. Journal of Defense Resources Management (JoDRM), 7(2), 159-164.

C, M. S. Van, Vicere, A. A., White, A. F., Robinson, G. S., \& Wick, C. W. (2008). Human Resource (Vol. 15, Issue $1)$.

Coll, J. E. (2008). A study of academic advising satisfaction and its relationship to student worldviews. Journal of College Student Retention: Research, Theory and Practice, 10(3), 391-404. https://doi.org/10.2190/CS.10.3.g

Committee, E. P., \& Reflections, P. (2017). EDU / EDPC (2016) 23 / ANN2 / REV1 for Official Use. 2016, 1-115.

Creswell, J. W. (2014). Research Design. In زاهاى نفتى انرزىشركت ملى يخش فر آرده /

Dopson, S., Ferlie, E., McGivern, G., Fischer, M. D., Ledger, J., Behrens, S., \& Wilson, S. (2016). The impact of leadership and leadership development in higher education: a review of the literature and evidence. In Leadership Foundation in Higher Education Research and Development. (Issue April 2016).

Ellis, Y., Daniels, B., \& Jauregui, A. (2010). The effect of multitasking on the grade performance of business students. Research in Higher Education Journal, 8, 1-10.

Endi Sarwoko, E. S. (2013). Entrepreneurial Characteristics and Competency as Determinants of Business Performance in SMEs. IOSR Journal of Business and Management, 7(3), 31-38. DOI: https://doi.org/10.9790/487x-0733138.

Garavan, T. N., \& Mcguire, D. (2001). Competencies and workplace learning: Some reflections on the rhetoric and the reality. In Journal of Workplace Learning, 13(4). DOI: https://doi.org/10.1108/13665620110391097

Halim, P., Swasto, B., Hamid, D., \& Firdaus, M. R. (2014). The Influence of Product Quality, Brand Image, and Quality of Service to Customer Trust and Implication on Customer Loyalty (Survey on Customer Brand Sharp Electronics Product at the South Kalimantan Province). European Journal of Business and Management, 6(29), 159-166.

Harackiewicz, J. M., \& Hulleman, C. S. (2010). The Importance of Interest: The Role of Achievement Goals and Task Values in Promoting the Development of Interest. Social and Personality Psychology Compass, 4(1), 4252. DOI: https://doi.org/10.1111/j.1751-9004.2009.00207.x.

Hoe, L. C., \& Mansori, S. (2018). The Effects of Product Quality on Customer Satisfaction and Loyalty: Evidence from Malaysian Engineering Industry. International Journal of Industrial Marketing, 3(1), 20. https://doi.org/10.5296/ijim.v3i1.13959

Igwe, A. (2014). Effective Human Resource Management as Tool for Organizational Success. European Journal of Business and Management, 6(39), 210-219.

Jaques, E. (2018). Organizational Leadership Practices. Requisite Organization, January 2001, 269-285. DOI: https://doi.org/10.4324/9781315088846-14.

Kipp. (2008). KIPP: Leadership framework and competency model. 
Lierse, S. (2016). Outstanding university lecturers: Ambitious altruists or mavericks of the Academy? Australian Journal of Teacher Education, 41(12), 1-12. DOI: https://doi.org/10.14221/ajte.2016v41n12.1.

Mine, Y., Hiraishi, H., \& Mizoguchi, F. (2001). Collaboration of networked home electronics using multi-agent technology. Annual Conference of the North American Fuzzy Information Processing Society - NAFIPS, 5(9), 2648-2652. DOI: https://doi.org/10.1109/nafips.2001.943641.

Mpele Lekhanya, L., \& Lucky Dlamini, H. (2017). Customer's perception towards product quality of automotive SMEs operating in Metropolitan areas, and consideration of environmental impact. Environmental Economics, 8(1), 36-45. DOI: https://doi.org/10.21511/ee.08(1).2017.04.

Mporananayo, N., \& Andala, H. O. (2018). Career Guidance and Students' Academic Performance in Higher Learning Institutions in Rwanda. A Case Study of Nyarugenge District. 23(12), 72-80. DOI: https://doi.org/10.9790/0837-2312057280.

Nassazi, A. (2013). Effects of Training On Employee Performance. Evidence from Uganda. Business Economics and Tourism, 57.

Nindiani, A., Hamsal, M., \& Purba, H. H. (2018). Product and Service Quality Analysis: An Empirical Study of Customer Satisfaction in a Bakery. Binus Business Review, 9(2), $95 . \quad$ DOI: https://doi.org/10.21512/bbr.v9i2.4257.

Okoye, P. V. C., \& Ezejiofor, R. A. (2013). The Effect of Human Resources Development on Organizational Productivity. International Journal of Academic Research in Business and Social Sciences, 3(10), 250-268. DOI: https://doi.org/10.6007/ijarbss/v3-i10/295.

Organizational Management: (2015) https://doi.org/10.2174/97816810805051150101.

Park, C. (2003). Engaging students in the learning process: The learning journal. Journal of Geography in Higher Education, 27(2), 183-199. DOI: https://doi.org/10.1080/03098260305675.

Razak, I., Nirwanto, N., \& Triatmanto, B. (2016). Journal of Marketing and Consumer Research www.iiste.org ISSN. An International Peer-Reviewed Journal, 30(2012), 59-68.

Revenio C. Jalagat, J. (2017). Leading and Managing People and Organizational Change: Individual and Organizational Benefits and Its Value on Staff Development. Business. Management and Economics Research, $3(8), 146-150$.

Russo, D. (2016). Competency Measurement Model. European Conference on Quality in Official Statistics, 1-29.

Ruttoh, M. J. K. (2015). Planning and Implementation of Guidance and Counseling Activities in Secondary Schools: A Case of Kamariny Division of Keiyo District, Kenya. Journal of Education and Practice, 6(5), 1-5.

Saleem, B. A., Ghafar, A., Ibrahim, M., Yousuf, M., \& Ahmed, N. (2015). Product Perceived Quality and Purchase Intention withConsumer Satisfaction. Global Journal of Management and Business Research: E Marketing, 15(1), p21-28.

Saleh, Mohammed, R. M., Nusari, M., Ameen, A., \& Alrajawy, I. (2018). Leadership in the organization: A Conceptual Review. International Journal of Management and Human Science (IJMHS), 2(4), 52-59.

Schmidt, F. A. (2017). Digital Labour Markets in the Platform Economy: Mapping the Political Challenges of Crowd Work and Gig Work. Freidrich Ebert Stiftung, March, 1-32.

Shaharudin, J., Angely, G. S. N., Anita, J., \& Khin, T. M. (2012). Examining the Product Quality Attributes That Influences Customer Satisfaction Most When the Price Was Discounted: A Case Study in Kuching Sarawak Curtin University of Technology Sarawak Campus. International Journal of Business and Social Science, 3(23), 221-237.

Sherratt, A. (1991). Sacred and profane substances: the ritual use of narcotics in later Neolithic Europe. Sacred and Profane: Proceedings of a Conference on Archaeology, Ritual and Religion, Oxford 1989, 9519, $50-64$. https://doi.org/ISSN: 2230-9519.

Speiser, M., \& Lang, P. (2018). Education and'. 2017(May 2017).

$\mathrm{Su}, \mathrm{F}$., \& Wood, M. (2012). What makes a good university lecturer? Students' perceptions of teaching excellence. Journal of Applied Research in Higher Education, 4(2), 142-155. DOI: https://doi.org/10.1108/17581181211273110.

Sydänmaanlakka, P. (2003). Intelligent leadership and leadership competencies: developing a leadership framework for intelligent organizations.

Thomas, K. (2017). UNIT4. 4. Leadership vs management. Landscape Management, 56(6), 10.

Winterton, J., Delamare-Le Deist, F., \& Stringfellow, E. (2006). Typology of knowledge, skills and competences. In Cedefop Reference Series. 